\title{
Stone (1932) revisited: What does his finding of superior maze learning in half-wild rats mean? *
}

\author{
ROBERT BOICE \\ iniversity of .Missouri. Columbia. Ho. 65201
}

Hybrid offspring of wild and albino parents outperformed both types of parent stocks of rats in shuttlebox avoidance, thus replicating Stone (1932). But this is not necessarily a demonstration of behavioral heterosis, or hybrid vigor, as has been popularly assumed. Demonstration of depression of learning ability in either parent strain awaits research with carefully inbred strains of both wild and domestic rats.

Behavioral heterosis. or hybrid vigor, is assumed to indicate a trait of obvious survival value (Bruell, 1964). Thus. for example, Smart (1970) and Schlesinger \& Wimer (1967) found hybrid mice more efficient in operant conditioning and avoidance learning than either parent strain. This is apparently the result of inbreeding depression of learning ability in the parent strains of mice (Bruell. 1967): behavior traits of greatest adaptive value are supposed to diminish most due to inbreeding (Falconer. 1960).

Assumptions that laboratory learning tasks measure obviously adaptive behaviors and that inbreeding in captivity brings diminution of learning ability may contribute to the belief that the laboratory rat has suffered an intellectual decline compared to its wild progenitor (Robinson, 1965: Lockard, 1968).

In one of the earliest attempts to measure the learning ability of wild rats. Stone (1932) found that exploratory activities and maze performance were apparently inhibited in captive wild rats. So, in comparison, laboratory rats showed much better maze performance. But hybrid offspring of wild and domestic rats showed performance superior to that of laboratory rats. Stone simply interpreted this to be a function of stronger food-drive in the hybrids, although the result can be explained as hybrid vigor (Robinson, 1965). In the tradition of psychologists who assume a superiority of wild rats over domestic rats. Stone speculated "that wild strains or their near relatives may actually possess greater native learning ability [p. 50]." If learning ability has been depressed by the inbreeding of domestication (Boice, 1973), then perhaps hybrid offspring of wild and laboratory rats will show a vigor of social behaviors (Boice, 1972) and learning behaviors not seen in laboratory rats.

The present study is an extension of this idea to shuttlebox avoidance in wild Norway rats, laboratory rats. and wild $\mathrm{x}$ domestic hybrid rats.

*Reprints: R. Boice. 209 McAlester Hall. University of Missouri. Columbia. Mo. 65201. I thank Professor D. D. Thiessen for valuable comments and criticisms of an earlier version of this article.

\section{METHOD \\ Subjects}

The Ss were 20 adult ( 100 to 120 days old) male rats (Rattus noriegicus) of each of three stocks: (a) first-generation. or $F_{1}$. rats bred from wild rats. pregnant at capture. from an Athens County. Ohio. land-fill (Boice. 1971a): (b) albino rats of Sprague-Dawley descent and an undefined breeding history: (c) hybrid offspring from seven litters of albino mothers bred with wild-caught fathers.

It should be noted that terminology used here varies from that of many studies with hybrid animals. Reports from this laboratory have consistently reserved the label of $\mathrm{r}$, for first-generation wild rats in captivity. whereas 1 ; used elsewhere may designate first-generation hybrids. First-generation wild rats were used instead of wild-caught rats in the present study because the former have laboratory raising experience equivalent to that of albino rats and because wild $\mathrm{I}_{1} \mathrm{~s}$ appear to show better avoidance performance than do wild-caught rats (Boice. 1970a).

All Ss were housed individually from weaning. with free access to water and Wayne Lab Blox. None of the rats had a known history of handling.

\section{Apparatus}

The shuttlebox had two chambers, each $50 \times 15 \times 50 \mathrm{~cm}$ high one white and one black. separated by a guillotine door. The Ss were watched via overhead mirrors. Stainless steel grids. spaced $1.5 \mathrm{~cm}$ center to center. Were charged. when appropriate. in series with neon bulbs (NE 2) with 20 microA at $60 \mathrm{~V}$ de.

\section{Procedure}

Transfers were made with a plastic handling box (Tighe. 1965). All Ss were trained for 200 consecutive trials. 100 trials in each direction. in a single session. Trials were signaled by the opening of the guillotine door. If the rat failed to cross to the opposite chamber (i.e.. avoid) within $5 \mathrm{sec}$. shock was delivered to the chamber until the rat escaped by crossing to the opposite chamber. The door was closed immediately after the rat avoided or escaped. Half the rats in each group had a 10 -sec ITI in the black chamber and a 100-sec ITI in the white chamber. and half the rats had the opposite combination.

\section{RESULTS}

Figure 1 depicts the course of avoidance responding in either direction for all three stocks of rats. The most salient result is the clear superiority in all groups of avoidance responding toward the side with longer ITI. This is yet another confirmation of the Weisman. Denny. \& Zerbolio (1967) finding that approach behavior in avoidance conditioning is mediated by relaxation cues that are better associated with the long ITI side (Denny. 1969).

Avoidance responding toward the short side (i.e.. from the 100-sec ITI side) was significantly different (all differences reported as significant $<.01$ ) between groups only in the final block of 10 trials according to t tests. Responding toward the long side was significantly different between all groups over all trials. according to an analysis of variance and a Duncan range test. Overall. the avoidance performance of the hybrid rats was superior to that of either of the other two groups. 


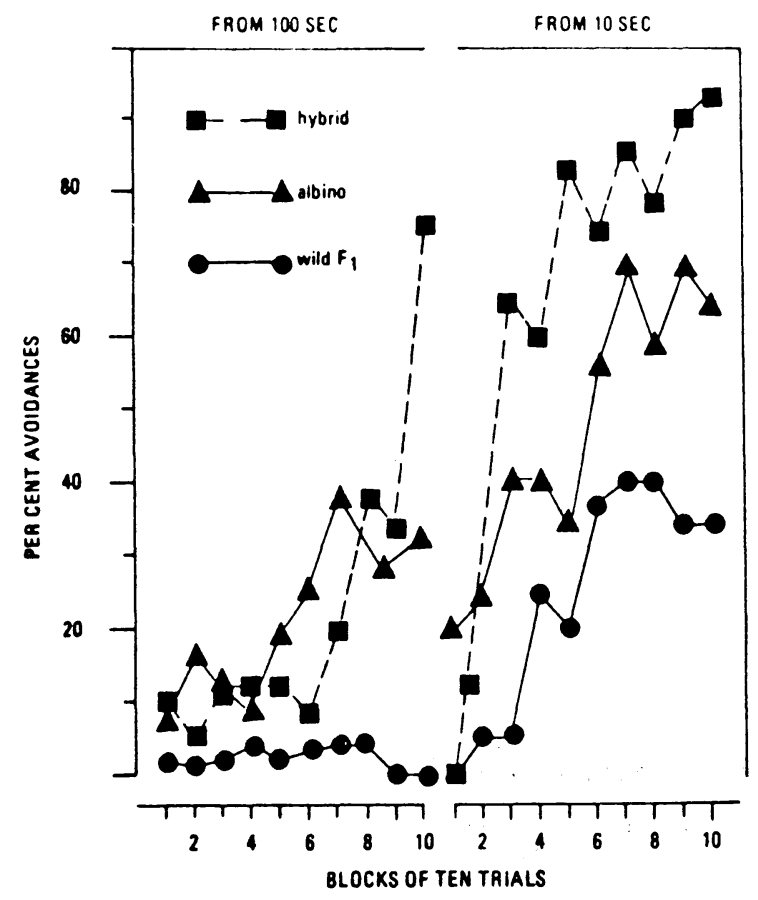

Fig. 1. Avoidance responding in two directions, from the side with the 100-sec ITI and from the side with the 10-sec ITI. The three groups of rats were from stocks of fully wild, first-generation $\left(F_{1}\right)$ rats, from stocks of albino rats, and from hybrid of fspring of wild and albino rats of the first generation.

Albino rats generally were intermediate in performance; wild $F_{1}$ rats always performed the poorest.

\section{DISCUSSION}

The finding that hybrid offspring of wild and laboratory rats outperform either of the parent types of rats in shuttlebox avoidance is an extension of Stone's (1932) comparison in a Lashley maze. But is this also a demonstration of behavioral heterosis? Manosevitz (1972) lists two cautions for such an interpretation. First, demonstration of heterosis is usually limited to studies in which both parent strains were inbred. In the present study. only one stock of rats. the albinos. might be assumed partially homozygous. although the breeding history of either type rat is not known. For example. local populations of rodents in the wild may be quite homozygous. Second. the generality of this apparent behavioral heterosis cannot be assumed on the basis of a single cross.

Equally important, the present study (and Stone's) tested hybrid offspring from only albino female $\mathrm{x}$ wild-caught males. Without data from the reciprocal cross. it is equally logical to assume that the hybrid effect is but a genotype-specific maternal phenomenon.

Even if, as the geneticist Robinson (1965) assumes. this type of result does demonstrate behavioral heterosis. what are the implications for the study of domestication in Norway rats? The logic of Bruell (1967) seems to dictate that hybrid vigor of avoidance performance indicates a depression of that trait in one parent stock, presumably the domestic rats. Perhaps, then. the relatively poor performance of the wild $\mathrm{l}$, s was due to confoundings from emotionality induced by captivity generally and the apparatus specifically. Hughes \& Boice (1973) found that when problems of apparent emotionality were reduced to a near minimum. shuttlebox aroidance by wild $l$, rats was indistinguishable from that by laboratory rats. Conversely. it could even be argued that depression of learning ability had occurred in the wild stock who profit better in nature from unlearned deferse reactions than from gradually acquired avoidance (Bolles. 1970). Moreover, domestic rats might have elaborated learning abilities as a result of conditions peculiar to captivity and domestication (Thorpe. 1965; Tinbergen. 1965; Boice, 1971b). So the problem would appear to be one of deciding which parent stock had suffered the depression. But the premise developed here gnores a viable alternative: Hybrid vigor may exceed either parent type and vet the overall fitness might have declined because coadapted gene complexes have broken down in crossing.

Perhaps the superior avoidance responding of the hybrid rats was simply due to their noticeably higher level of activity in the apparatus. Higher activity level has been shown to be a positive correlate of avoidance performance in other situations (Boice, Boice. \& Dunham. 1968; Boice, 1970b). and first-generation hybrids similar to those of the present study were remarkably active in social contact contrasted to wild and domestic rats (Boice, 1972). The well-known neophobia of wild rats (Barnett, 1958) and other wild rodents (Price. 1972) seems to contradict this notion. However, Barnett now emphasizes the quality of neophilia in wild rodents (Barnett \& Smart, 1970). Price \& Loomis (1973) found wild rats to be more active than domestic rats in a novel environment; high levels of activity in novel situations may benefit wild rodents who must learn new pathways quickly if they are to survive. 1

Thus, what the present experiment shows is that Stone's (1932) finding of superior performance in half-wild rats is quite replicable. It does not, however, prove anything concerning depression of learning ability in either parent strain. Properly done, such a proof would demand the quixotic search for an "adaptive" task in the laboratory and the gargantuan feat of inbreeding strains of rats from both wild and domestic stocks with common parentage in each case. The resultant limitation of generality due to selection of original parents and the investment of time in generations and space for housing the strains would appear to condemn this and related issues of domestication to the realm of speculation for some time to come.

\section{REFERENCES}

Barnett, S. A. Experiments on "neophobia" in wild and laboratory rats. British Journal of Psychology, 1958, 49 195-201.

Barnett, S. A., \& Smart, J. L. Activity of inbred and $F_{1}$ mice in a residential maze. Quarterly Journal of Experimental Psychology, 1970, 22, 494-502.

Boice, R. Effect of domestication on avoidance learning in the Norway rat. Psychonomic Science, 1970a, 18, 13-14.

Boice, $R$. Avoidance learning in active and passive frogs and toads. Journal of Comparative \& Physiological Psychology, $1970 \mathrm{~b}, 70,154-156$.

Boice, R. Laboratorizing the wild rat (Rattus norvegicus) Behavior Research Methods \& Instrumentation, 1971a, 3, 177-182.

Boice, R. Is learning unnatural? Paper presented at the Psychonomic Society, St. Louis, 1971b.

Boice, $\mathrm{R}$. Some behavioral tests of domestication in Norway.rats. Behaviour, 1972,42,198-231.

Boice, R. Domestication. Psychological Bulletin, 1973, in press. Boice, R., Boice, C., \& Dunham, A. E. Role of docility in avoidance: Gerbils and kangaroo rats in a shttlebox. Psychonomic Science, 1968, 10, 381-382.

Bolles, R. C. Species-specific defense reactions and avoidance learning. Psychological Review. 1970, 77, 32-48.

Bruell, J. H. Inheritance of behavioral and physiological characters of mice and the problem of heterosis. American Zoologist, 1964, 4, 125-138.

Bruell, J. H. Behavioral heterosis. In J. Hirsh (Ed.). Behavior-genetic analysis. New York: McGraw-Hill. 1967.

Denny, M. R. Relaxation theory and experiments. In F. R. Brush (Ed.). A cersice conditioning and learning. New York: Academic Press, 1969.

Falconer, D. S. Introduction to quantitative genetics. London: Oliver \& Boyd. 1960.

Hughes. C. W.. \& Boice. R. Aroidance. one and two wav, in wild and domestic rats. Journal of Comparative \& Physiological Psychology. 1973. in press.

Lockard. R. B. The albino rat: A defensible choice or a bad habit? American Psichologist. $1968,23,734-742$. 
Manosevitz. M. Behavioral heterosis: Food competition in mice. Journal of Comparative \& Physiological Psychology. 1972. 79. 46-50.

Price. E. O. Novelty-induced self-food deprivation in wild and semi-domestic deer mice (Peromyscus maniculatus bairdii). Behaviour, 1972, 41, 91-104.

Price. E. O.. \& Loomis. S. Maternal influence on the response of wild and domestic Norway rats to a novel environment. Developmental Psychobiology 1973, in press.

Robinson. R. Genetics of the Noruay rat. Oxford: Pergamon Press. 1965.

Schlesinger, K., \& Wimer. R. Genotype and conditioned aroidance learning in the mouse. Journal of Comparative \& Physiological Psychology, 1967, 63, 139-141.

Smart. J. L. Trail-and-error behavior of inbred and $F_{1}$ hybrid mice. Animal Behaviour. 1970, 18. 445-453.

Stone. C. P. Wildness and savageness in rats of different strains. In $\mathrm{K}$. S. Lashley (Ed.). Studies in the dynamics of behavior.
Chicago: Lniversity of Chicago Press. 19.32.

Thorpe. W. H. Learning and instinct in animals London: Methuen, 1963.

Tighe, T. J. A handling device for small animals. Journal of the Experimental Analvsis of Behavior. 1965,8,261-262.

Tinbergen. N. Animal behavior. New York: Time. Inc.. 1965

Weisman. R. G.. Denny. M. R.. \& Zerbolio, D. J. Discrimination based on differential nonshock confinement in a shuttlebox. Journal of Comparative \& Physiological Psychology. 1967.63. 34-38.

\section{NOTE}

1. Personal communication. Prof. L. O. Price. Department of Forest Zoology. Syracuse Lniversity. 1973.

(Received for publication June 11. 1973.)

\section{Chemical and electrical stimulation of the rat lateral hypothalamus*}

\author{
NEIL M. KIRSCHNER \\ Bowling Green State Lniversity, Bow'ling Green. Ohio 43402 \\ and \\ ROBERT A. LEVITT \\ Southern Illinois Liniversity. Carbondale, Ill. 62901
}

In a preliminary study, it was not found possible to obtain clear-cut data on the interaction between chemical and electrical stimuli, both applied to the same locus in the lateral hypothalamus. In a subsequent study, the sites in the lateral hypothalamus from which water ingestion can be elicited by electrical or chemical stimulation of the brain were found to have little overlap. However, chemical stimulation drinking sites in the zona incerta and lateral hypothalamus were found to all also be sites from which electrical self-stimulation could be elicited. Since nondrinking sites to chemical stimulation could also be found in this area and were also self-stimulation sites, no specific relationship between chemically elicited drinking and electrical self-stimulation can be drawn.

Some of the most interesting findings to be reported in the physiological literature during the past two decades concern the demonstrated ability to elicit consummatory behaviors which are stimulus bound to the application of an appropriate chemical or electrical stimulant to specific subcortical loci. The application of a chemical stimulant to subcortical loci has been found to elicit eating and drinking behaviors (Grossman. 1960), as well as stimulus-bound sexual behavior (Fisher, 1956). Similar behaviors have been elicited upon the application of an electrical stimulant to selected neural areas (Miller. 1960: Caggiula \& Hoebel. 1966: Mogenson \& Sevenson,

*Supported by USPHS Research Grant MH-14381 and by the Office of Research and Projects of Southern Illinois University at Carbondale. Send reprint requests to Robert $A$. Levitt.
1966). Related to these findings is the observation that electrical stimulation applied to many areas of the brain can serve as a very potent reinforcer. Olds and Milner (1954) reported high rates of responding in the Skinner box situation. with only short trains of electrical pulses delivered to a subcortical area serving as the reinforcer. This barpressing operant response was later termed self-stimulation (S-S) by Brady (1958). Since first reported. S-S has been obtained from many subcortical areas and from all species tested. It is interesting to note that at all neural sites where stimulus-bound consummatory behaviors have been elicited upon the application of an electrical stimulus. S-S behavior is also found (Margules \& Olds. 1962: Caggiula \& Hoebel. 1966: Coons \& Cruce. 1968). The study to be reported attempted to examine the interaction between electrical and chemical modes of stimulation.

Several exploratory investigations have preceded the experiment to be reported. These investigations employed a chemode technique developed by Fisher (1969), which allows for simultaneous electrical and chemical stimulation at the same neural site. or either mode of stimulation alone. Using this technique. an attempt was made to determine whether an anticholinergic chemical (atropine or scopolamine), which had been previously found to block cholinergically induced chemical drinking (Stein \& Seifter, 1962), could selectively block electrically induced drinking upon its application to the subcortical electrical drinking site. Both a self-stimulatory and an automatically delivered electrical stimulus paradigm were investigated. Under the S-S paradigm. only Ss who both self-stimulated and drank to the self-delivered stimulus were employed. Under the automatic delivery: paradigm. only Ss who displayed stimulus-bound 